\title{
Exercise-Induced U-Wave Changes in Patients With Coronary Artery Disease
}

\section{_ Correlation With Tomographic Thallium-201 Myocardial Imaging -}

\author{
Hiroyuki Miyakoda, M.D., Akihiro Endo, M.D., Masahiko Kato, M.D. \\ Tatsuo Kato, M.D., Hiroki Omodani, M.D., Shuichi Osaki, M.D. \\ Toru Kinugawa, M.D., Akira Hoshio, M.D. \\ and Hiroto Mashiba, M.D*
}

\begin{abstract}
We studied the relation between exercise-induced U-wave changes and the site of a reversible defect in tomographic ${ }^{201} \mathrm{Tl}$ myocardial imaging. Coronary artery disease and control groups consisted of 116 and 42 patients, respectively. In the anteroapical-ischemia group $(n=37)$, the sensitivity of $U$-wave inversion in the anterior precordial leads for ischemia was $62 \%$ (23/37) and that of prominent $U$-waves without an increase in the height of the T-wave in the inferior limb leads was $57 \%$ (21/37). In this group, 18 patients (49\%) met both criteria (18 [78\%] of 23 patients with the former; 18 [86\%] of 21 patients with the latter). In the posterior-ischemia group $(\mathrm{n}=59)$, the sensitivity of prominent $\mathrm{U}$ waves with a decrease in the height of the $\mathrm{T}$-wave in the anterior precordial leads for ischemia was $63 \%(37 / 59)$ and that of U-wave inversion in the inferior limb leads was $20 \%(12 / 59)$. In this group, 12 patients $(20 \%)$ met both criteria (12 [32\%] of 37 patients with the former; all 12 patients with the latter). The specificity of U-wave criteria was $100 \%$. In the anteroapical and posteriorischemia group $(n=20)$, the sensitivity of $U$-wave criteria for anteroapical and posterior ischemia was $85 \%(17 / 20)$ and $40 \%$ (8/20), respectively. In conclusion, U-wave criteria are not only specific but also sensitive for myocardial ischemia determined by ${ }^{201} \mathrm{Tl}$ imaging.
\end{abstract}

(Jpn Circ J 1996; 60: 641-651)

$\mathbf{E}^{x}$ XERCISE-INDUCED U-wave inversion has been reported to be a specific, but not sensitive, marker for coronary artery disease, and especially for proximal left anterior descending coronary artery disease ${ }^{1,2}$ Some studies $^{3,4}$ have demonstrated that exercise-induced U-wave inversion in the inferior limb leads may be related to right and/or left circumflex coronary artery disease. Recently, transient prominent U-

Key words:

Coronary artery disease

Exercise test

U-wave waves with a decrease in the height of the $\mathrm{T}$-wave in the right precordial leads during spontaneous angina or exercise have been reported to be a sensitive and specific marker for right or left circumflex coronary artery disease 5 , 6 Previous studies ${ }^{1-6}$ demonstrated a high prevalence of high-grade coronary artery narrowing in patients with abnormal U-wave changes. On the other hand, exercise-stress tomographic ${ }^{201} \mathrm{Tl}$ myocardial imaging is increasingly being used to detect myocardial ischemia. However, the incidence of abnormal U-wave

(Received June 23, 1995; accepted December 8, 1995)

First Department of Internal Medicine, Tottori University School of Medicine, Yonago, Japan

*Kure Kyosai Hospital, Kure, Japan

Mailing address: Hiroyuki Miyakoda, M.D., First Department of Internal Medicine, Tottori University School of Medicine, 36-1 Nishimachi, Yonago 683, Japan 
changes (inversion and prominence) in patients with a positive test for exercise-stress tomographic $201 \mathrm{Tl}$ myocardial imaging has not been determined. In addition, the distribution patterns of $\mathrm{U}$-wave changes in the anterior precordial and inferior limb leads in individual patients have not been analyzed. The purpose of this study was to evaluate the diagnostic accuracy of $\mathrm{U}$ wave criteria according to the distribution of U-wave changes for detecting myocardial ischemia using tomographic ${ }^{201} \mathrm{Tl}$ imaging for diagnosis.

\section{METHODS}

\section{Subjects}

The patients in this study were retrospectively selected from among subjects who underwent exercise-stress tomographic ${ }^{201} \mathrm{Tl}$ myocardial imaging and coronary arteriography and left ventriculography. Luminal narrowing was measured using calipers on arteriograms after the administration of nitrate. The results of coronary arteriography and left ventriculography were assessed according to the criteria proposed by the AHA? Coronary The coronary artery disease group consisted of 116 patients (79 men and 37 women, mean age 63 years, range 35 to 84) who had predominantly exertional angina, coronary artery narrowing of $90 \%$ or more and a positive test for exercise-stress 201 Tl imaging. The control group consisted of 42 patients who had no coronary artery narrowing of more than $50 \%$ and a negative test for exercise-stress ${ }^{201} \mathrm{Tl}$ myocardial imaging. Control subjects were divided into 2 subgroups: group $I=27$ patients $(9$ men and 18 women, mean age 61 years, range 47 to 76 ) who had a negative test according to ST criteria; group $\mathrm{II}=15$ patients $(4 \mathrm{men}$ and 11 women, mean age 60 years, range 49 to 76 ) who had a positive test according to ST criteria. Patients with abnormal left ventricular contractility (none, dyskinetic or aneurysmal) were excluded. Patients with intraventricular conduction disturbance, atrial fibrillation, congenital or valvular heart disease, or idiopathic cardiomyopathy were also excluded.

Supine bicycle exercise was begun at 25 watts, and the work rate was increased by 25 watts every $3 \mathrm{~min} .{ }^{201} \mathrm{Tl}(111 \mathrm{MBq})$ was injected intravenously at peak exercise, and patients continued to exercise for an additional min. A modified 12-lead electrocardiogram (according to the Mason and Likar $\operatorname{method}^{8}$ ) was recorded at rest, every minute during exercise, and after 1,2 and 3 min of recovery. The ST-segment, T-wave and U-wave were analyzed in the anterior precordial leads $\left(\mathrm{V}_{2}\right.$ to $\left.\mathrm{V}_{5}\right)$ and in the inferior limb leads (II, III and aVF). The end-point of exercise was the development of moderate anginal chest pain, severe shortness of breath or severe leg fatigue, new or additional ST-segment depression $(0.2 \mathrm{mV}$ or more at $80 \mathrm{msec}$ from the $\mathrm{J}$ point) or ST-segment elevation $(0.1 \mathrm{mV}$ or more at $40 \mathrm{msec}$ from the $\mathrm{J}$ point) in at least 1 lead, except aVR, aVL and V1, compared with the level at rest, or the achievement of $85 \%$ of the age-adjusted predicted maximum heart rate (target heart rate). A significant change in the level of the ST segment was defined as new or additional horizontal or down-sloping depression $(0.1 \mathrm{mV}$ or more) or elevation $(0.05 \mathrm{mV}$ or more $)$ at $1 \mathrm{~min}$ of recovery compared with the level at rest. Exercise-induced U-wave inversion was defined as new discrete negative deflection of $0.05 \mathrm{mV}$ or more within the TP segment. Neither negative deflection which was not separated from the $\mathrm{T}$-wave terminal nor a biphasic wave (initial inversion followed by positive deflection) was used as a positive criterion of U-wave inversion? A prominent exercise-induced $\mathrm{U}$-wave was defined if the amplitude of a positive U-wave was increased $0.05 \mathrm{mV}$ or more compared with the level at rest. A significant change in the height of a T-wave was defined as $0.1 \mathrm{mV}$ or more. Patients whose U-waves could not be analyzed because of TP-segment shortening (less than $120 \mathrm{msec}$ ) were excluded. Tomographic ${ }^{201} \mathrm{Tl}$ imaging was performed using a gamma camera (Hitachi, GAMMA-VIEW) equipped with a high-resolution, low-energy parallel-hole collimator and interfaced to a dedicated computer system (Hitachi, HARP). Initial imaging was begun $10 \mathrm{~min}$ after the termination of exercise and delayed imaging was repeated $4 \mathrm{~h}$ later. Thirty-two projections over a 180-degree arc were obtained with a $64 \times 64$ matrix. Short-axis, vertical long-axis and horizontal longaxis tomograms were reconstructed at a 
thickness of 1-pixel $(5.6 \mathrm{~mm})$ per slice. The left ventricle was divided into 6 segments; septal, anterior, apical, inferoposterior, anterolateral and posterolateral. Images were interpreted by three observers. A defect was classified as reversible (partial or complete redistribution) or nonreversible (no redistribution or equivocal). A consensus of the 3 observers was taken. Reversible defect was used as a positive criterion for myocardial ischemia.

\section{Statistical Analysis}

Data are shown as the mean \pm standard deviation or as a percentage. Data were analyzed by the Yates-corrected chi-square test or the McNemar test. A value of $p<$ 0.05 was considered significant.

\section{RESULTS}

\section{Cardiac Catheterization}

Thirty-four patients had left anterior descending coronary artery disease in the absence of right and left circumflex coronary artery disease, 50 patients had right and/or left circumflex coronary artery disease in the absence of left anterior descending coronary artery disease and 32 patients had both left anterior descending coronary artery disease and right and/or left circumflex coronary artery disease. Two patients in the latter group had left main coronary artery disease.

\section{Exercise Variables}

The number of patients with each endpoint of exercise in control groups I and II and the coronary artery disease group was, respectively, as follows; moderate anginal chest pain: 0, 0 and 75 patients; ST-segment depression: 0, 9 and 15 patients; ST-segment elevation: 0,0 and 7 patients; leg fatigue: 11 , 5 and 16 patients; target heart rate: 16,1 and 3 patients. Peak work load in the 3 groups was $66 \pm 22,70 \pm 22$ and $51 \pm 19$ watts, and heart rate at peak exercise was $130 \pm 12$, $119 \pm 9$ and $112 \pm 17$ beats/min, respectively.

\section{Exercise-induced $U$-wave Changes in Control Subjects}

Control group I $(n=27)$ : None of the patients showed U-wave inversion. Three patients $(11 \%)$ had prominent $\mathrm{U}$-waves with an increase in the height of the $\mathrm{T}$-wave in the anterior precordial leads and/or in the inferior limb leads. One patient (4\%) had prominent U-waves with a decrease in the height of the T-wave in both the anterior precordial leads and the inferior limb leads.

Control group II $(n=15)$ : None of the patients showed U-wave inversion. One patient $(7 \%)$ had prominent U-waves with an increase in the height of the T-wave in both the anterior precordial leads and the inferior limb leads. Two patients $(13 \%)$ had prominent U-waves with a decrease in the height of the T-wave in both the anterior precordial leads and the inferior limb leads.

\section{Tomographic ${ }^{201} \mathrm{Tl}$ Myocardial Imaging in Patients With Coronary Artery Disease}

Thirty-seven patients (33 patients with left anterior descending coronary artery disease in the absence of right and left circumflex coronary artery disease and 4 patients with both left anterior descending coronary artery disease and right and/or left circumflex coronary artery disease) had a reversible defect in the anterior and/or apical segments in the absence of a reversible defect in the inferoposterior and posterolateral segments, 59 patients (49 patients with right and/or left circumflex coronary artery disease in the absence of left anterior descending coronary artery disease and 10 patients with both left anterior descending coronary artery disease and right and/or left circumflex coronary artery disease) had a reversible defect in the inferoposterior and/or posterolateral segments in the absence of a reversible defect in the anterior and apical segments, and 20 patients (1 patient with left anterior descending coronary artery disease in the absence of right and left circumflex coronary artery disease, 1 patient with right coronary artery disease in the absence of left anterior descending and left circumflex coronary artery disease and 18 patients with both left anterior descending coronary artery disease and right and/or left circumflex coronary artery disease) had a reversible defect in both the anterior and/or apical segments and the inferoposterior and/or posterolateral segments.

\section{Relation Between Exercise-induced $U$-wave Changes and the Site of a Reversible ${ }^{201} \mathrm{Tl}$ Defect}


TABLE I RELATIONSHIP BETWEEN EXERCISE-INDUCED U-WAVE CHANGES IN THE ANTERIOR PRECORDIAL LEADS AND THE INFERIOR LIMB LEADS IN PATIENTS WITH A REVERSIBLE 201T1 DEFECT IN THE ANTERIOR AND/ OR APICAL SEGMENTS $(\mathrm{N}=37)$

\begin{tabular}{|c|c|c|c|c|c|c|}
\hline & \multicolumn{6}{|c|}{ Inferior limb leads } \\
\hline & Inversion & Unchanged & $\begin{array}{c}\text { Prominent } \\
(T \downarrow)\end{array}$ & $\begin{array}{c}\text { Prominent } \\
(T \rightarrow)\end{array}$ & $\begin{array}{c}\text { Prominent } \\
(T \uparrow)\end{array}$ & Total \\
\hline \multicolumn{7}{|c|}{ Anterior precordial leads } \\
\hline Inversion & 0 & 5 & 10 & 8 & 0 & 23 \\
\hline Unchanged & 0 & 11 & 2 & 1 & 0 & 14 \\
\hline Prominent & 0 & 0 & 0 & 0 & 0 & 0 \\
\hline Total & 0 & 16 & 12 & 9 & 0 & 37 \\
\hline
\end{tabular}

$T \downarrow=$ with a decrease in the height of the $T$-wave; $T \rightarrow=$ without a significant change in the height of the $T$ wave; $T \uparrow=$ with an increase in the height of the $T$-wave.

\section{Initial Delayed}

\section{Vertical long-axis}
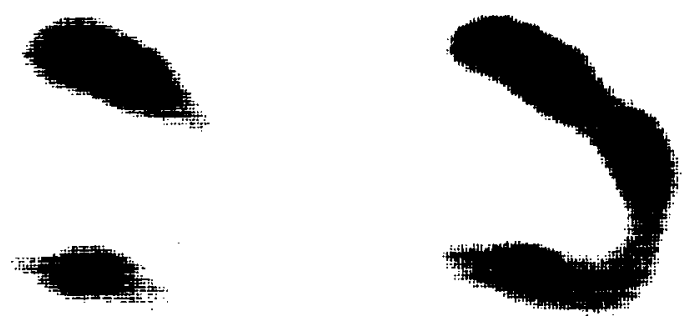

Horizontal long-axis
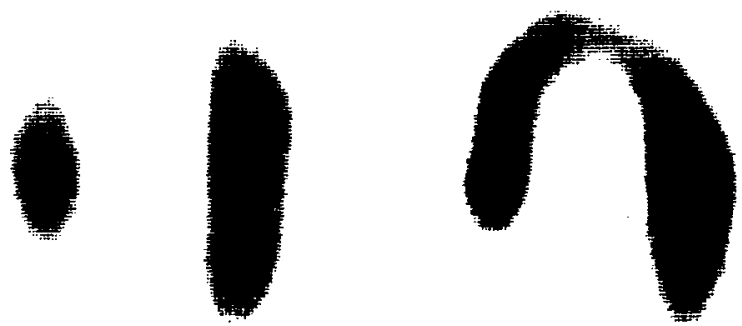

Fig 1- a) Exercise-stress tomographic ${ }^{201} \mathrm{Tl}$ myocardial imaging in a patient with left anterior descending coronary artery disease. The septal, anterior and apical segments show a reversible defect.

(I) Patients with a reversible ${ }^{201} \mathrm{Tl}$ defect in the anterior and/or apical segments in the absence of a reversible defect in the inferoposterior and posterolateral segments (anteroapical-ischemia group, $\mathrm{n}=37$ ) (Table I)

Anterior precordial leads: Twelve patients (32\%) showed ST-segment elevation. Twenty patients (54\%) showed ST-segment depression without ST-segment elevation (80\% of 25 patients without ST-segment elevation). Twenty-three patients (62\%) (8[67\%] of 12 patients with ST-segment elevation, 14 [70\%] of 20 patients with STsegment depression without ST-segment elevation, and 1 [20\%] of 5 patients without ST-segment depression or elevation) showed $\mathrm{U}$-wave inversion, but none of the patients had a prominent U-wave.

Inferior limb leads: Twenty-four patients (65\%) (10 [83\%] of 12 patients with STsegment elevation and $14[56 \%]$ of 25 


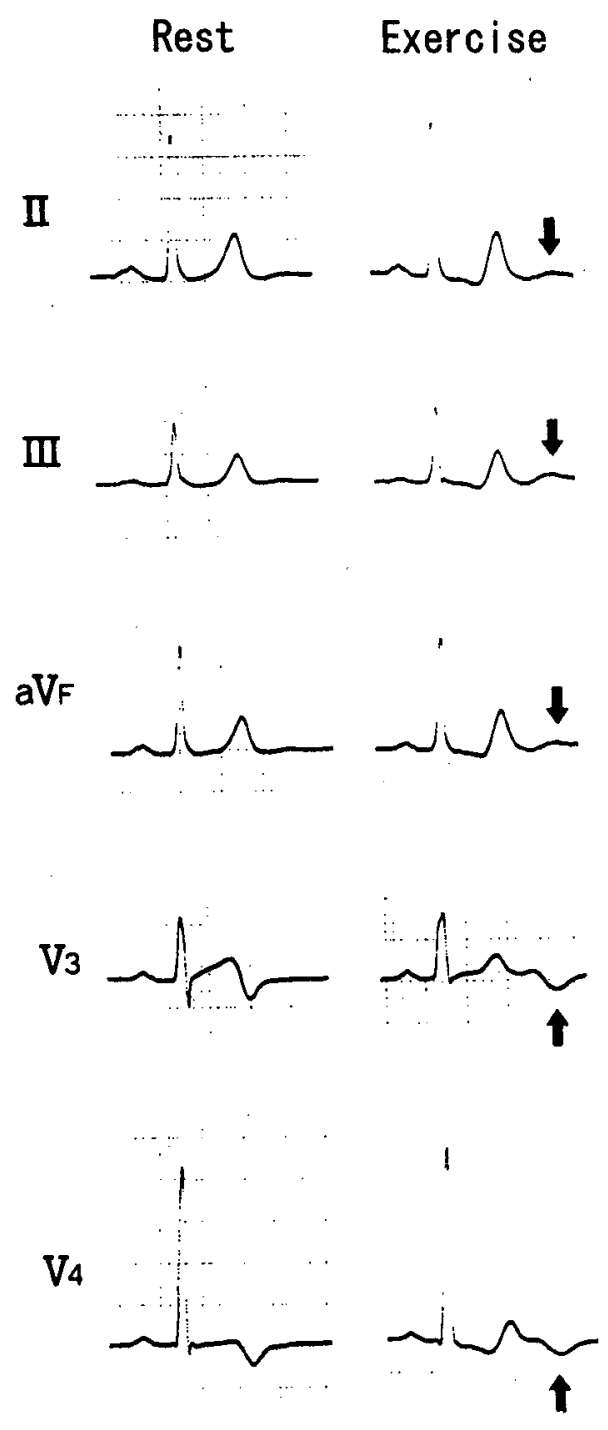

Fig 1- b) Exercise-stress electrocardiogram in the patient in Fig 1-a) Exercise-induced $\mathrm{U}$-wave inversion and prominent $\mathrm{U}$-waves without an increase in the height of the Twave are shown in the anterior precordial leads and the inferior limb leads, respectively.

patients without ST-segment elevation in the anterior precordial leads) showed STsegment depression, but none of the patients showed ST-segment elevation. Twenty-one patients $(57 \%)(8[67 \%]$ of 12 patients with ST-segment elevation and 13 [52\%] of 25 patients without ST-segment elevation in the anterior precordial leads) had prominent U-waves without an increase in the height of the T-wave ( $p=N S$ vs $U$-wave inversion in the anterior precordial leads), but none of the patients showed U-wave inversion.

Distribution patterns of U-wave changes in the anterior precordial and inferior limb leads in individual patients: Eighteen patients $(49 \%)$ had both U-wave inversion in the anterior precordial leads and prominent U-waves in the inferior limb leads (18 [78\%] of 23 patients with the former; 18 [86\%] of 21 patients with the latter).

A typical case is shown in Fig 1-a) and $1-b)$

(II) Patients with a reversible ${ }^{201} \mathrm{Tl}$ defect in the inferoposterior and/or posterolateral segments in the absence of a reversible defect in the anterior and apical segments (posterior-ischemia group, $\mathrm{n}=59$ ) (Table II)

Anterior precordial leads: Fifty-two patients $(88 \%)$ showed ST-segment depression $(\mathrm{p}=\mathrm{NS}$ vs patients without ST-segment elevation in the anteroapical-ischemia group), but none of the patients showed ST-segment elevation. Thirty-seven patients $(63 \%)(34[65 \%]$ of 52 patients with ST-segment depression and $3[43 \%]$ of 7 patients without ST-segment depression) had prominent U-waves with a decrease in the height of the T-wave, and 1 patient had prominent $U$-waves with an increase in the height of the T-wave, but none of the patients had U-wave inversion.

Inferior limb leads: Thirty-four patients $(57 \%)$ showed ST-segment depression $(\mathrm{p}=$ NS vs patients without ST-segment elevation in the anteroapical-ischemia group), but none of the patients showed ST-segment elevation. Twelve patients $(20 \%)$ had Uwave inversion $(\mathrm{p}<0.05$ vs prominent $\mathrm{U}$-waves with a decrease in the height of the $\mathrm{T}$-wave in the anterior precordial leads). One patient $(2 \%)$ had prominent U-waves with increased an increase in the height of the T-wave (the same patient had prominent U-waves with an increase in the height of the T-wave in the anterior precordial leads).

Distribution patterns of U-wave changes in the anterior precordial and inferior limb leads in individual patients: Twelve patients (20\%) had both prominent U-waves with a decrease in the height of the T-wave in the anterior precordial leads and $\mathrm{U}$-wave inversion in the inferior limb leads (12 [32\%] of 37 patients with the former; all 12 patients with the latter).

A typical case is shown in Fig 2-a) and 2-b) 
TABLE II RELATIONSHIP BETWEEN EXERCISE-INDUCED U-WAVE CHANGES IN THE ANTERIOR PRECORDIAL LEADS AND THE INFERIOR LIMB LEADS IN PATIENTS WITH A REVERSIBLE 201TI DEFECT IN THE INFEROPOSTERIOR AND/OR POSTEROLATERAL SEGMENTS $(\mathrm{N}=59)$

\begin{tabular}{lcccc}
\hline & & Inferior limb leads & \\
\cline { 2 - 5 } & Inversion & Unchanged & Prominent & Total \\
\hline Anterior precordial leads & & & & \\
$\quad$ Inversion & 0 & 0 & 0 & 0 \\
Unchanged & 0 & 21 & 0 & 21 \\
Prominent $(T \downarrow)$ & 12 & 25 & 0 & 37 \\
Prominent $(T \rightarrow)$ & 0 & 0 & 0 & 1 \\
Prominent $(T \uparrow)$ & 0 & 0 & 1 & 59 \\
Total & 12 & 46 & 1 & 1 \\
\hline
\end{tabular}

$T \downarrow=$ with a decrease in the height of the $T$-wave; $T \rightarrow=$ without a significant change in the height of the $T$ wave; $T \uparrow=$ with an increase in the height of the $T$-wave.

\section{Initial}

\section{Vertical \\ long-axis}

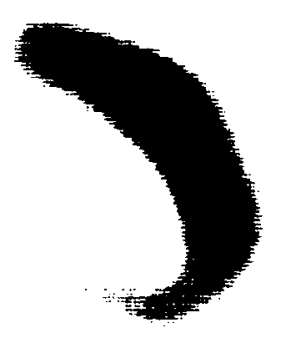

Short-axis

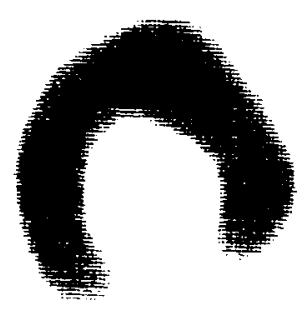

Delayed
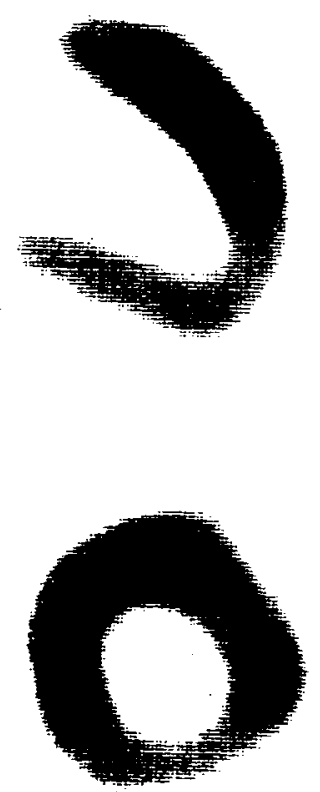

Fig 2- a) Exercise-stress tomographic ${ }^{201} \mathrm{Tl}$ myocardial imaging in a patient with right coronary artery disease. The inferoposterior segment shows a reversible defect.

(III) Patients with a reversible ${ }^{201} \mathrm{Tl}$ defect in both the anterior and/or apical segments and the inferoposterior and/or posterolateral segments (anteroapical and posterior-ischemia group, $\mathrm{n}=20$ )

Anterior precordial leads: Three patients (15\%) showed ST-segment elevation, and 15 patients $(75 \%)$ showed ST-segment depression without ST-segment elevation. Seventeen patients $(85 \%)$ had U-wave inversion $(\mathrm{p}=\mathrm{NS}$ vs anteroapical-ischemia group), and 1 patient (5\%) had prominent U-waves with a decrease in the height of the T-wave $(\mathrm{p}<0.01$ vs posterior-ischemia group).

Inferior limb leads: Sixteen patients $(80 \%)$ showed ST-segment depression, but none of the patients showed ST-segment elevation. Seven patients $(35 \%)$ had U-wave inversion $(\mathrm{p}=\mathrm{NS}$ vs posterior-ischemia group and $\mathrm{p}<0.01$ vs $\mathrm{U}$-wave inversion in the anterior precordial leads), and 3 patients (15\%) had 


\section{Rest Exercise}
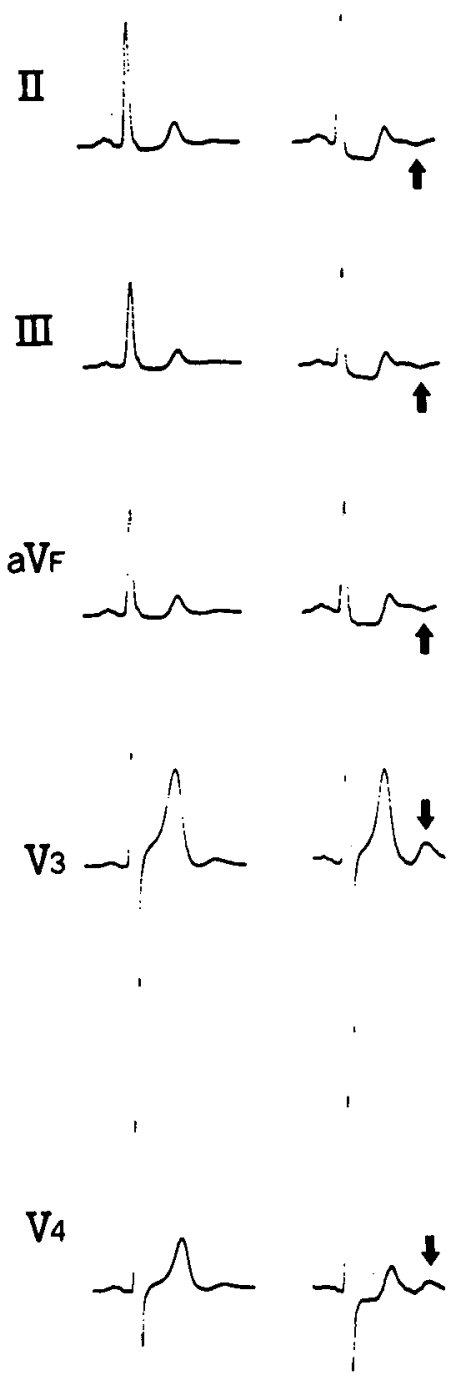

Fig 2- b) Exercise-stress electrocardiogram in the patient in Fig 2-a) Exercise-induced prominent $\mathrm{U}$-waves with a decrease in the height of the T-wave and U-wave inversion are shown in the anterior precordial leads and the inferior limb leads, respectively.

prominent U-waves without an increase in the height of the T-wave $(p<0.01$ vs anteroapical-ischemia group).

\section{Diagnostic Accuracy of $U$-wave Criteria for Detecting Myocardial Ischemia}

U-wave criteria for anteroapical ischemia: In the anteroapical-ischemia group, the sensitivity of $\mathrm{U}$-wave inversion in the anterior precordial leads was $62 \%$, and that of prominent $\mathrm{U}$-waves without an increase in the height of the $\mathrm{T}$-wave in the inferior limb leads was $57 \%$. The specificity of the former was $100 \%$. The specificity of the latter was $96 \%$ in control group I, $87 \%$ in control group II and $100 \%$ in the posterior-ischemia group.

U-wave criteria for posterior ischemia: In the posterior-ischemia group, the sensitivity of U-wave inversion in the inferior $\operatorname{limb}$ leads was $20 \%$, and that of prominent $\mathrm{U}$-waves with a decrease in the height of the $\mathrm{T}$-wave in the anterior precordial leads was $63 \%$. The specificity of the former was $100 \%$. The specificity of the latter was $96 \%$ in control group I, $87 \%$ in control group II and $100 \%$ in the anteroapical-ischemia group.

If prominent U-waves induced simultaneously in the anterior precordial leads and the inferior limb leads were considered a negative criterion for myocardial ischemia, the specificity of prominent U-waves was $100 \%$ in control groups I and II.

In the anteroapical and posterior-ischemia group, the sensitivity of U-wave criteria for anteroapical and posterior ischemia was $85 \%$ $(17 / 20)$ and $40 \%(8 / 20)$, respectively.

\section{DISCUSSION}

The present study demonstrates the relation between exercise-induced U-wave changes and the site of myocardial ischemia determined by a reversible defect in tomographic ${ }^{201} \mathrm{Tl}$ myocardial imaging. U-wave inversion in the anterior precordial leads and prominent $\mathrm{U}$-waves without an increase in the height of the $\mathrm{T}$-wave in the inferior limb leads are markers for myocardial ischemia in the anterior and/or apical segments, and prominent $\mathrm{U}$-waves with a decrease in the height of the T-wave in the anterior precordial leads and $U$-wave inversion in the inferior limb leads are markers for myocardial ischemia in the inferoposterior and/ or posterolateral segments. Prominent Uwaves may represent reciprocal changes for $\mathrm{U}$-wave inversion. Thus, U-wave criteria are not only specific but also sensitive for myocardial ischemia.

Detecting the site of myocardial ischemia is important in evaluating the severity of coronary artery disease. In this study, the distribution of exercise-induced ST-segment elevation reflected the site of myocardial ischemia. On the other hand, there was no 
significant difference in the incidence of exercise-induced ST-segment depression in both the anterior precordial leads and the inferior limb leads between patients with a reversible ${ }^{201} \mathrm{Tl}$ defect in the anterior and/or apical segments and those with a defect in the inferoposterior and/or posterolateral segments in the absence of ST-segment elevation. Our results indicate that exerciseinduced ST-segment depression in the anterior precordial leads is not specific for myocardial ischemia in the anterior and/or apical segments and that in the inferior limb leads is not specific for myocardial ischemia in the inferoposterior and/or posterolateral segments. This finding is consistent with the results from previous studies using planar ${ }^{201} \mathrm{Tl}$ myocardial imaging for diagnosis ${ }^{10-12}$ Thus, the distribution of exercise-induced ST-segment depression in the anterior precordial and inferior limb leads may be of little value in detecting the site of myocardial ischemia.

Previous studies in which coronary arteriographical narrowing was used for diagnosis demonstrated that exercise-induced U-wave inversion was specific, but not sensitive, for coronary artery disease $1^{-4}$ Gerson et $\mathrm{al}^{1}$ observed U-wave inversion in a modified CC5 or VL lead during treadmill exercise in $25(35 \%)$ of 71 patients with left anterior descending or left main coronary artery narrowing of $75 \%$ or more in the absence of previous anterior myocardial infarction, in 2 (4\%) of 57 patients with coronary artery disease who had no significant left anterior descending or left main coronary artery narrowing, and in only 1 of 82 patients without significant coronary artery narrowing. Tsuzuki et $\mathrm{al}^{2}$ reported that the prevalence of left anterior descending or left main coronary artery narrowing of $75 \%$ or more was significantly higher in 20 patients with U-wave inversion in CM5 (18 patients), CC5 (20 patients), anterior precordial (15 patients) or inferior limb leads (1 patient) during treadmill exercise than in 36 patients without $U$-wave inversion $(17 / 20[85 \%]$ vs $20 / 36[56 \%], p<0.05)$. In addition, none of 38 normal men had U-wave inversion. These investigators ${ }^{1,2}$ concluded that exercise-induced U-wave inversion may be specific, especially for left anterior descending coronary artery disease. Yamamoto et $\mathrm{al}^{3}$ reported that $25(33 \%)$ of 76 patients with coronary artery narrowing of $75 \%$ or more or ergonovine-induced coronary artery spasm in the absence of previous myocardial infarction had $\mathrm{U}$-wave inversion during treadmill exercise, while none of 35 normal men had U-wave inversion. Among these 25 patients, U-wave inversion was seen in the anterior precordial leads in $20(80 \%)$, in the anterior precordial and inferior limb leads in $4(16 \%)$, and in the inferior limb leads in $1(4 \%)$. Four $(80 \%)$ of the 5 patients with U-wave inversion in the inferior limb leads had right and/or left circumflex coronary artery narrowing. Shimono et $\mathrm{al}^{4}$ reported that $29(34 \%)$ of 85 patients with coronary artery narrowing of $50 \%$ or more in the absence of previous myocardial infarction and $5(8 \%)$ of 62 patients without significant coronary artery narrowing had exerciseinduced U-wave inversion. Of the 29 patients with coronary artery narrowing, U-wave inversion was seen in the anterior precordial leads in $22(76 \%)$, in the anterior precordial and inferior limb leads in $6(21 \%)$ and in the inferior limb leads in $1(3 \%)$. All 7 patients with $U$-wave inversion in the inferior limb leads had right and/or left circumflex coronary artery narrowing. In these reports 3,4 a total of 12 patients with left anterior descending coronary artery narrowing or spasm in the absence of right and left circumflex coronary artery narrowing and spasm had U-wave inversion. Eleven (92\%) of the 12 patients had U-wave inversion in the anterior precordial leads and $1(8 \%)$ had U-wave inversion in the anterior precordial and inferior limb leads. On the other hand, a total of 7 patients with right and/or left circumflex coronary artery narrowing in the absence of left anterior descending and left main coronary artery narrowing and spasm had U-wave inversion. Among these 7 patients, U-wave inversion was seen in the anterior precordial and inferior limb leads in $4(57 \%)$, in the inferior limb leads in 2 $(29 \%)$, and in the anterior precordial leads in $1(14 \%)$. Data from these reports 3,4 indicate that exercise-induced U-wave inversion in the inferior limb leads may be specific for right or left circumflex coronary artery disease, while that in the anterior precordial leads may not always be specific for left anterior descending coronary artery disease. 
Ikeda et al $^{13}$ evaluated the spatial distribution of exercise-induced U-wave inversion in patients with coronary artery disease using body surface electrocardiographic mapping. They compared these data with the site of myocardial ischemia determined by planar ${ }^{201} \mathrm{Tl}$ imaging. The distribution patterns of $\mathrm{U}$-wave inversion were divided into 2 types; 1) upper-type, in which the mini of the isopotential map within the TP segment was located on the row of standard chest leads or above; and 2) lower-type, in which the mini was located below the row of standard chest leads. Upper-type U-wave inversion had a sensitivity of $59 \%(19 / 32)$ and a specificity of $100 \%$ (38/38) for anterior ischemia. Lowertype U-wave inversion had a sensitivity of $26 \%(7 / 27)$ and a specificity of $100 \%$ (43/43) for inferior ischemia. These investigators concluded that upper-type U-wave inversion indicated anterior ischemia and lower-type $\mathrm{U}$-wave inversion indicated inferior ischemia. Their results suggest that the location of the mini of the U-wave potential may reflect the site of myocardial ischemia.

Recently, transient prominent $\mathrm{U}$-waves have been reported to be useful as markers for left circumflex or right coronary artery disease. Hasegawa et $\mathrm{al}^{5}$ studied electrocardiograms during spontaneous angina or exercise tests in 84 patients with coronary artery narrowing of $75 \%$ or more and electrocardiograms during exercise tests in 28 normal men. In their report, transient prominent U-waves with a decrease in the height of the T-wave in the right precordial leads $\left(V_{1}\right.$ to $\left.V_{3}\right)$ were observed in $19(83 \%)$ of 23 patients with the most severe narrowing in the left circumflex coronary artery and in $21(62 \%)$ of 34 patients with the most severe narrowing in the right coronary artery. However, none of 27 patients with the most severe narrowing in the left anterior descending coronary artery and only $1(4 \%)$ of 28 normal men showed prominent U-waves with a decrease in the height of the T-wave. They proposed that transient prominent $U$-waves with a decrease in the height of the $\mathrm{T}$-wave were a sensitive and specific marker for left circumflex or right coronary artery disease. Chikamori et al ${ }^{6}$ assessed the diagnostic accuracy of this marker in a large number of patients. Their study of the relation between U-wave changes during treadmill exercise and individual coronary artery narrowing of $75 \%$ or more demonstrated that the sensitivity and specificity of prominent U-wave criterion in the precordial leads for left circumflex or right coronary artery disease were $52 \%$ and $88 \%$, respectively. On the other hand, prominent $\mathrm{U}$-waves in the inferior limb leads were not specific for coronary artery disease. Chikamori et $\mathrm{al}^{14}$ subsequently studied exercise-induced $\mathrm{U}$-wave changes in patients with one-vessel coronary artery disease with narrowing of $75 \%$ or more. In their report, U-wave inversion was observed in $12(24 \%)$ of 66 patients with left anterior descending coronary artery disease, in $1(4 \%)$ of 23 patients with left circumflex coronary artery disease and in $2(15 \%)$ of 13 patients with right coronary artery disease. On the other hand, prominent U-waves were observed in $8(12 \%), 11(48 \%)$ and $8(62 \%)$ of the respective patient groups. They concluded that negative and prominent U-waves in precordial leads are markers which can be used to differentiate between left anterior descending coronary artery disease and left circumflex or right coronary artery disease. However, the distribution patterns of $\mathrm{U}$ wave changes in the anterior precordial and inferior limb leads in individual patients were not analyzed.

The location of coronary artery narrowing does not always indicate the site of exerciseinduced myocardial ischemia. A reversible defect in exercise-stress ${ }^{201} \mathrm{Tl}$ myocardial imaging is specific for regional myocardial ischemia. We used a reversible defect in tomographic ${ }^{201} \mathrm{Tl}$ imaging for diagnosing myocardial ischemia and evaluated the accuracy of exercise-induced U-wave changes in anterior precordial and inferior limb leads in detecting myocardial ischemia.

There is a variety of exercise-induced negative deflection within the TP segment (negative deflection which is separated from the T-wave terminal, negative deflection which is not separated from the $T$-wave terminal, and a biphasic wave [initial inversion followed by positive deflection]). Recently, Miwa et $\mathrm{al}^{9}$ reported that transient U-wave inversion could be classified as initial inversion or terminal inversion and that the latter was observed in association with anginal attacks in patients with variant 
angina, whereas the former seemed to be related to elevated blood pressure rather than to myocardial ischemia. In our study, neither negative deflection which was not separated from the T-wave terminal nor a biphasic wave was used as a positive criterion of U-wave inversion. U-wave inversion in the anterior precordial leads was not only specific but also sensitive for myocardial ischemia in the anterior and/or apical segments, and U-wave inversion in the inferior limb leads was specific, but not sensitive, for myocardial ischemia in the inferoposterior and/or posterolateral segments. The high specificity of U-wave inversion suggests that terminal-type U-wave inversion is also specific for exercise-induced myocardial ischemia. The higher sensitivity of U-wave inversion in our study than in previous studies ${ }^{1-4,13}$ may be due to the high specificity of a reversible defect in tomographic ${ }^{201} \mathrm{Tl}$ imaging for myocardial ischemia.

The incidence of $U$-wave inversion has been reported to be high along with exercise-induced or spontaneous ST-segment elevation?,15 Yamamoto et $\mathrm{al}^{3}$ reported that $11(85 \%)$ of 13 patients with exerciseinduced ST-segment elevation in the anterior precordial leads had U-wave inversion. Matsuguchi et al ${ }^{15}$ reported that $16(67 \%)$ of 24 patients with variant angina and STsegment elevation in the precordial leads had U-wave inversion during spontaneous attacks. However, in our study, the incidence of U-wave inversion in patients with ST-segment elevation was similar to that in patients with ST-segment depression in the absence of ST-segment elevation in the anteroapical-ischemia group $(67 \%$ vs $70 \%, \mathrm{p}=\mathrm{NS})$. In a previous study, we found that $8(62 \%)$ of 13 patients with one-vessel disease of the left anterior descending coronary artery and exercise-induced STsegment elevation in the absence of previous myocardial infarction had U-wave inversion, while none of 15 patients with previous anterior myocardial infarction and exerciseinduced ST-segment elevation in the absence of significant coronary artery narrowing had $\mathrm{U}$-wave inversion ${ }^{16}$ Thus, U-wave inversion may be a specific marker for myocardial ischemia among patients with exerciseinduced ST-segment elevation.

In this study, exercise-induced prominent
U-waves with a decrease in the height of the T-wave in the anterior precordial leads and those without an increase in the height of the T-wave in the inferior limb leads were sensitive and specific for myocardial ischemia in the inferoposterior and/or posterolateral segments and for myocardial ischemia in the anterior and/or apical segments, respectively. However, prominent U-waves induced simultaneously in the anterior precordial leads and the inferior limb leads may be a negative marker for myocardial ischemia. The addition of this finding to the prominent $\mathrm{U}$-wave criteria increased the specificity for myocardial ischemia. U-wave inversion was predominantly observed in leads facing the ischemic site. Prominent $\mathrm{U}$-waves due to myocardial ischemia may reflect reciprocal changes for U-wave inversion.

In the anteroapical and posterior-ischemia group, the incidence of exercise-induced Uwave inversion in the anterior precordial leads, which was similar to that in the anteroapical-ischemia group, was higher than the incidence of U-wave inversion in the inferior limb leads, which was similar to that in the posterior-ischemia group. In this group, the incidence of exercise-induced prominent U-waves was low. Thus, in patients with myocardial ischemia at both sites, the predictability based on U-wave criteria may be high for myocardial ischemia in the anterior and/or apical segments but low for myocardial ischemia in the inferoposterior and/or posterolateral segments. This is one of the limitations of detecting myocardial ischemia based on $\mathrm{U}$-wave criteria.

The mechanism of exercise-induced $\mathrm{U}$ wave changes is still unknown. Exerciseinduced U-wave changes disappear sooner in the recovery period than ST-segment changes. However, we conclude that analysis of the distribution patterns of U-wave changes is useful for detecting myocardial ischemia.

\section{Acknowledgments}

We thank Dr. Chiaki Shigemasa for encouragement. We also thank Kenichi Endo and Tsuyoshi Nishio (Division of Radioisotope, Tottori University Hospital) for their assistance and Drs. Noriyasu Noguchi, Hideyuki Kitamura, Tatsuhiko Matsumoto and Kazuhide Ogino for their cooperation. 


\section{REFERENCES}

1. Gerson MC, Phillips JF, Morris SN, McHenry PL: Exercise-induced U-wave inversion as a marker of stenosis of the left anterior descending coronary artery. Circulation 1979; 60: 1014-1020

2. Tsuzuki M, Shiki K, Kawai N, Kondo T, Yamauchi K, Yokota M, Hayashi H, Sotobata I: Clinical significance of exercise-induced $\mathrm{U}$-wave inversion in effort angina. Correlation with coronary angiographic findings (in Japanese). Heart 1983; 15: 188-193

3. Yamamoto M, Fu L, Iinuma H, Aizawa T, Takahashi N, Katoh K, Asanoi E: Clinical significance of exercise induced $U$ wave inversion in effort angina (in Japanese). Jpn J Electrocardiol 1984; 5: $383-389$

4. Shimono T, Kubota I, Ikeda K, Tsuiki K, Yasui S: Clinical significance of exercise-induced negative $\mathrm{U}$ waves. J Jpn Soc Intern Med 1987; 76: 810-817

5. Hasegawa K, Fujiwara T, Sawayama T, Nezuo S, Nakano M, Tadaoka S, Nakamura T, Kakumae S, Kawahara Y, Inoue S: Angina-induced transient positive $U$ wave in right precordial leads. A marker of left circumflex artery/right coronary artery stenosis (in Japanese). Heart 1988; 20: 1033-1039

6. Chikamori T, Yamada M, Takata J, Furuno T, Yamasaki F, Doi Y: Exercise-induced prominent $\mathrm{U}$ waves as a marker of significant narrowing of the left circumflex or right coronary artery. $A m J$ Cardiol 1994; 74: 495-499

7. AHA Committee Report: A reporting system on patients evaluated for coronary artery disease. Circulation 1975; 51: 5-40

8. Mason RE, Likar I: A new system of multiple-lead exercise electrocardiography. Am Heart $J$ 1966; 71: 196-205

9. Miwa K, Miyagi Y, Fujita M, Fujiki A, Sasayama S: Transient terminal $U$ wave inversion as a more specific marker for myocardial ischemia. Am Heart $J$ 1993; 125: $981-986$

10. Dunn RF, Freedman B, Bailey IK, Uren RF, Kelly DT: Localization of coronary artery disease with exercise electrocardiography: Correlation with ${ }^{201} \mathrm{Tl}$ myocardial perfusion scanning. Am J Cardiol 1981; 48: $837-843$

11. Fox RM, Hakki A, Iskandrian AS: Relation between electrocardiographic and scintigraphic location of myocardial ischemia during exercise in one-vessel coronary artery disease. Am J Cardiol 1984; 53: $1529-1531$

12. Kaul S, Kiess M, Liu P, Guiney TE, Pohost GM, Okada RD, Boucher CA: Comparison of exercise electrocardiography and quantitative thallium imaging for one-vessel coronary artery disease. Am J Cardiol 1985; 56: 257-261

13. Ikeda K, Yamaki M, Matsui M, Hanashima K, Nakamura K, Tonooka I, Meguro M, Tsuiki K, Yasui S: Spatial distribution of exercise-induced ST-segment depression and U-wave inversion in identifying the ischemic site in patients with coronary artery disease. Jpn Circ J 1989; 53: 695-706

14. Chikamori T, Takata J, Furuno T, Yabe T, Matsumura Y, Kitaoka H, Doi Y: Usefulness of U-wave analysis in detecting significant narrowing limited to a single coronary artery. Am J Cardiol 1995; 75: 508-509

15. Matsuguchi T, Koiwaya Y, Nakagaki O, Takeshita A, Nakamura $\mathrm{M}$ : Transient $\mathrm{U}$ wave inversion during variant angina. Am Heart $J$ 1984; 108: 899-904

16. Miyakoda $\mathrm{H}$, Kato $\mathrm{M}$, Noguchi $\mathrm{N}$, Omodani $\mathrm{H}$, Osaki S, Matsumoto T, Kinugawa T, Hoshio A, Kotake H, Mashiba $\mathrm{H}$ : Exercise-induced STsegment elevation: Role of left ventricular wall motion abnormalities and coronary artery narrowing. Jpn Circ J 1995; 59: 725-735 